\title{
Updates to the Canadian Notifiable Disease Surveillance System and its interactive website
}

\author{
S Totten ${ }^{1 *}$, A Medaglia ${ }^{1}$, S McDermott ${ }^{1}$
}

\begin{abstract}
The Canadian Notifiable Disease Surveillance System (CNDSS) provides data on diseases that have been identified as priorities for public health monitoring and control. Several advances that have been made on Notifiable Diseases Online, the CNDSS interactive website, are consistent with the Government of Canada's commitment to Open Data. This article provides an update on changes in case definitions that have been made since the case definitions were last published in 2009, and describes updates that have been made to the interactive website since 2013.

Changes were made to the case definitions of five diseases. For hepatitis $C$, the new case definition now distinguishes between acute and chronic infection. For cyclosporiasis, the probable case definition requires an epidemiologic link, with the clarification that this would likely be due to exposure to a common food source. For rabies, the probable case definition now refers to detection of rabies-neutralizing antibody instead of specific antibody titres. For Lyme disease the revised confirmed and probable case definitions now identify five options for Lyme disease risk areas instead of endemic areas. For tuberculosis the revised case definition now includes nucleic acid amplification testing in addition to culture for diagnosis.

The Notifiable Diseases Online website is an interactive tool that enables users to create customized figures and tables. Since a major redesign in 2013, numerous changes have been made to the look and feel of the site. Figures and tables can now be extracted as Excel or PDF files and large datasets are exportable into Excel files for further analysis. Case definitions in the national surveillance system will be updated as needed and its interactive website will continue to be improved and updated in response to user comments.
\end{abstract}

This work is licensed under a Creative Commons Attribution 4.0 International License.

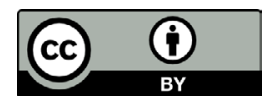

Affiliation

${ }^{1}$ Centre for Communicable Diseases and Infection Control, Public Health Agency of Canada, Ottawa ON

*Correspondence:

stephanie.totten@canada.ca

Suggested citation: Totten S, Medaglia A, McDermott S. Updates to the Canadian Notifiable Disease

Surveillance System and its interactive website. Can Commun Dis Rep 2019;45(10):257-61.

https://doi.org/10.14745/ccdr.v45i10a02

Keywords: surveillance, notifiable diseases, case definition, Canada, update

\section{Introduction}

Surveillance of health-related events is an essential function of public health and supports Canada's efforts to advance public health nationally and internationally. The Canadian Notifiable Disease Surveillance System (CNDSS) is operated by the Public Health Agency of Canada (PHAC). This national surveillance system monitors infectious diseases that have been identified collectively by the federal, provincial and territorial governments. It provides timely and accurate data to inform public health programs and policies (1). This is now part of the Government of Canada's Open Data initiative that aims to provide Canadians with access to data that are produced, collected and used across the federal government (2). Surveillance is one of the main sources of Open Data in public health.

\section{Background}

The national collection of data on communicable diseases was first undertaken in 1924 by the Dominion Bureau of Statistics (now Statistics Canada). This responsibility was transferred to Health Canada's Laboratory Centre for Disease Control in 1988, and then to PHAC (upon the Agency's creation) in 2004. These data are received and used under the legislative authority of the Statistics Act and the Department of Health Act.

Provincial and territorial laws mandate that healthcare providers, hospitals and laboratories report cases of certain conditions to public health authorities. These are generally called reportable diseases. Many reportable diseases are also national notifiable diseases (NNDs), but this is not uniformly true. Provincial/ territorial public health authorities report voluntarily on NNDs to the federal government, for national aggregation and reporting. 
For NNDs, the list of designated diseases is maintained through a collaborative federal/provincial/territorial process (3-5). Currently, there are 56 NNDs, and for the majority of diseases, cases are reported annually from provincial/territorial authorities to the CNDSS, along with basic demographic information on age and sex. A few diseases (i.e. HIV/AIDS, tuberculosis, West Nile virus, Creutzfeldt-Jakob disease, influenza and acute flaccid paralysis) are reported directly to PHAC disease-specific programs, due to the complexity of the disease or its surveillance system.

Case definitions in the CNDSS are intended to support public health activities rather than clinical diagnosis. Standardized case definitions for NND were first developed through a

federal/provincial/territorial process in 1991, with subsequent editions in 2000 (6) and 2009 (7). Following the 2009 revision, the decision was taken to make future updates on a case-by-case basis.

A rudimentary interactive website was launched for the CNDSS in 2001 to replace the printed annual reports. In 2013, a redesigned Notifiable Diseases Online (NDO) was launched in response to user feedback and new accessibility requirements. It included all CNDSS data (going back to 1924, where available). Since 2013, further enhancements have been made, including greater interactivity and more options in the chart function (1). Currently, approximately 600 unique users visit the site each month.

\section{Objectives}

The objectives of this article are to describe the process by which NND case definitions are updated, summarize revisions to five NND case definitions made since the 2009 CNDSS edition and summarize the recent enhancements to the NDO interactive online query tool.

\section{How National Notifiable Diseases case definitions are updated}

Case definition updates are coordinated through the Pan-Canadian Public Health Network (PHN). Case definition reviews may be initiated at any time of year if the need is identified by epidemiologic or laboratory programs at the federal or provincial/territorial level. Between 2009 and 2013, updated definitions were developed through informal federal/ provincial/territorial collaborations and reviewed by the PHN's Communicable and Infectious Disease Steering Committee (CIDSC) prior to implementation in national surveillance. In 2013, a more formal process was approved by the Public Health Network Council. This process includes an annual invitation for an expression of interest. When the decision is made to proceed, a technical task group is formed, conducts a review and makes recommendations to the CIDSC. Task groups include laboratory, epidemiology and clinical experts, as well as others nominated by provincial/territorial CIDSC members. Once approved by CIDSC, the new case definition is implemented for routine surveillance. Typically, most provinces and territories adopt the national case definitions for their own use; however, for some diseases, there are slight variations between the national case definitions and those used in provincial/territorial public health surveillance.

\section{Updates on five case definitions}

Since the publication of the 2009 edition of the CNDSS case definitions, five reviews have been conducted to revise case definitions (8). Three of the case definition reviews (hepatitis C, cyclosporiasis and rabies) were conducted prior to 2013 and two reviews (Lyme disease and tuberculosis) were conducted after the establishment of the Pan-Canadian Public Health Network protocol in 2013.

\section{Hepatitis C}

The 2009 national case definition for hepatitis C (7) did not distinguish between acute and chronic infection. The updated definition includes a definition of acute (recently acquired) hepatitis $C$ virus infection, using symptoms, serology and other clinical tests, or documented seroconversion within a 12-month period. All other hepatitis $C$ cases are to be reported under an unspecified category that includes chronic and resolved infections. This change in case definition is not expected to impact the total number of cases of hepatitis $C$ reported annually. However, it will allow for analysis of trends of recentlyacquired infection as a proxy for incidence. This case definition was approved by CIDSC in 2011.

\section{Cyclosporiasis}

The 2009 case definition for probable cyclosporiasis (7) was revised to align better with other enteric disease probable case definitions in Canada and the United States. Specifically, the revised definition requires probable cases to be epidemiologically-linked to a laboratory-confirmed case. An additional statement was added to the comments section to identify that direct person-to-person transmission is unlikely to occur and that an epidemiologic link is likely to be through exposure to a common food source. This change in case definition is not expected to impact the total number of cases of cyclosporiasis reported nationally, as the CNDSS reports only on confirmed cases. The change has no implications at the laboratory level, as the probable case definition is not based on laboratory criteria. This case definition was approved by CIDSC in 2012. 


\section{Rabies}

The 2009 case definition of probable rabies was changed, as the laboratory criteria were confusing. The 2009 case definition referred to specific antibody titres when, in fact, antibody thresholds are not necessary for the diagnosis of rabies. The reference to the titre of greater or equal to five in the probable case definition was removed and replaced with the phrase "detection of rabies-neutralizing antibody". In addition, the reference to the detection threshold of $0.5 \mathrm{IU} / \mathrm{ml}$ was removed from the Laboratory Comments section. The wording of the Laboratory Comments section was also changed to emphasize that serology should be used only in conjunction with additional testing for the diagnosis of rabies. These changes are not expected to affect the reporting of cases of this rare disease. As the Canadian Public Health Laboratory Network had already been consulted and was in agreement with all changes to this updated case definition, it was presented to CIDSC for information only in 2012.

\section{Lyme disease}

The 2009 case definition for Lyme disease (7) included very specific guidelines for the identification of an endemic area, which required extensive, resource-intensive surveillance by reporting jurisdictions. Evidence of exposure to environmental risk is recommended when using serologic methods to diagnose Lyme disease (9), so the revised case definition identifies five options for Lyme disease risk areas, including two methods of active field surveillance; passive tick surveillance; signals from human case surveillance; and validated predictive models. Additional details on appropriate clinical specimens for laboratory diagnosis were added. These changes are expected to improve the identification of Lyme disease risk and reporting of Lyme disease cases by provincial and territorial public health authorities. The changes to the national case definition are expected to increase the number of probable and confirmed cases, based on the five options to identify risk areas. This case definition was approved by CIDSC in 2016 and has been implemented in all jurisdictions except Saskatchewan.

\section{Tuberculosis}

The 2009 case definition (7) for tuberculosis included culture detection only for laboratory-confirmed cases. The revised case definition includes nucleic acid amplification testing, as it is increasingly used for laboratory confirmation of Mycobacterium tuberculosis infection. In addition, cases previously classified as "clinically-confirmed" are now referred to as "clinicallydiagnosed" and the criteria for these cases were updated to reflect those being used in practice in the reporting jurisdictions. These changes are not expected to impact national trends in tuberculosis surveillance data. This case definition was approved by CIDSC in early 2019, and will be implemented as of January 2020 for the reporting of 2019 annual tuberculosis data.

The updates to these case definitions are summarized in Table 1.
Table 1: Summary of revisions to case definitions of Nationally Notifiable Diseases: 2009-early 2019

\begin{tabular}{|c|c|c|c|}
\hline $\begin{array}{l}\text { Nationally } \\
\text { Notifiable } \\
\text { Disease } \\
\text { (year } \\
\text { changed) }\end{array}$ & $\begin{array}{c}\text { Summary of } \\
\text { change }\end{array}$ & Rationale & $\begin{array}{l}\text { Expected } \\
\text { impact on } \\
\text { national } \\
\text { trends }\end{array}$ \\
\hline $\begin{array}{l}\text { Hepatitis C } \\
\text { (2011) }\end{array}$ & $\begin{array}{l}\text { Case definition } \\
\text { now distinguishes } \\
\text { between acute } \\
\text { and chronic } \\
\text { infection }\end{array}$ & $\begin{array}{l}\text { Previous } \\
\text { definition } \\
\text { lacked detail } \\
\text { that was } \\
\text { available } \\
\text { in some } \\
\text { jurisdictions }\end{array}$ & $\begin{array}{l}\text { No change to } \\
\text { total number of } \\
\text { cases }\end{array}$ \\
\hline $\begin{array}{l}\text { Cyclosporiasis } \\
(2012)\end{array}$ & $\begin{array}{l}\text { The probable } \\
\text { case definition } \\
\text { now requires } \\
\text { cases to be } \\
\text { epidemiologically } \\
\text { linked to a } \\
\text { laboratory- } \\
\text { confirmed case } \\
\text { (likely through } \\
\text { a common food } \\
\text { source) }\end{array}$ & $\begin{array}{l}\text { To align better } \\
\text { with other } \\
\text { enteric disease } \\
\text { probable case } \\
\text { definitions in } \\
\text { Canada and the } \\
\text { United States }\end{array}$ & No change \\
\hline $\begin{array}{l}\text { Rabies, human } \\
(2012)\end{array}$ & $\begin{array}{l}\text { The probable } \\
\text { case definition } \\
\text { now includes } \\
\text { a "detection } \\
\text { of rabies- } \\
\text { neutralizing } \\
\text { antibody" instead } \\
\text { of specific } \\
\text { antibody titres }\end{array}$ & $\begin{array}{l}\text { Specific } \\
\text { antibody } \\
\text { titres are not } \\
\text { necessary for } \\
\text { the diagnosis of } \\
\text { rabies }\end{array}$ & No change \\
\hline $\begin{array}{l}\text { Lyme disease } \\
\text { (2016) }\end{array}$ & $\begin{array}{l}\text { The revised } \\
\text { case definition } \\
\text { identifies five } \\
\text { options for } \\
\text { determining } \\
\text { Lyme disease } \\
\text { risk areas rather } \\
\text { than requiring } \\
\text { evidence of an } \\
\text { endemic area }\end{array}$ & $\begin{array}{l}\text { Identifying } \\
\text { an endemic } \\
\text { area requires } \\
\text { extensive, } \\
\text { resource- } \\
\text { intensive } \\
\text { surveillance }\end{array}$ & $\begin{array}{l}\text { An increase } \\
\text { in the } \\
\text { identification of } \\
\text { confirmed and } \\
\text { probable cases }\end{array}$ \\
\hline $\begin{array}{l}\text { Tuberculosis } \\
(2019 ; \\
\text { effective } \\
\text { January 2020) }\end{array}$ & $\begin{array}{l}\text { The confirmed } \\
\text { case definition } \\
\text { now includes } \\
\text { nucleic acid } \\
\text { amplification } \\
\text { testing and } \\
\text { refinements to } \\
\text { the clinical case } \\
\text { definition }\end{array}$ & $\begin{array}{l}\text { Adding } \\
\text { NAAT and } \\
\text { refinements of } \\
\text { terms reflect } \\
\text { current best } \\
\text { practices }\end{array}$ & No change \\
\hline
\end{tabular}

\section{Updates to Notifiable Diseases Online}

Since its relaunch in 2013, annual updates have included improvements to the look and feel of the NDO interactive site. In 2017, a function was added for users to download their query and the resulting online data into a PDF or in a Microsoft Excel spreadsheet. In 2018, a new custom charts function was introduced that includes a variety of options for data outputs. For example, to obtain a simple chart of national 
trends for campylobacter and salmonella infections between 1991 and 2016, a user can simply identify these two diseases and the time period of interest, and a graph showing trends over time will automatically be created (Appendix 1a). Custom charts can also be created according to specifications (i.e. axis definitions and variable groupings), and filters can be applied as needed (i.e. by age group, sex and year). The benefits of customization include the ability to visualize data for multiple diseases, age groups and sex categories, according to user needs (Appendix 1b). Both simple and custom charts can then be exported into a PDF or Excel format.

It is now possible to extract a large aggregate dataset that includes any or all available NND data, for all available years since 1924. This function creates an Excel workbook containing all the data, with the data limitations and disease descriptions in the "Notes" tab and the data table in the "Data" tab. Data extracts can be broken down by age and sex from the year 1991 onwards. Updates planned for late 2019, include the exportation of comma-separated values file formats in the large data extract function, for easier importation into statistical analysis packages, as well as enhanced visualization of data reporting variations, which enable the user to understand with a quick look how nationally representative the data are for a given disease.

\section{Conclusion}

The CNDSS and the NDO provide open data on all 56 notifiable diseases in Canada and the interactive website has been improved to meet user needs. The revised case definitions and increased functionality of the website have enhanced the capacity for people who are interested in these data to access it and create useful tables and figures that are tailored to their information needs. These data can increase awareness of infectious disease trends and inform the development and evaluation of public health programs and policies at the national level. This accessible database is also consistent with the Government of Canada's commitment to Open Data and Open Science, with the overall goal of increasing our national capacity to prevent, mitigate and control communicable and infectious diseases in Canada. Improvements to the functionality of the website will continue to be made; users of the CNDSS and NDO are encouraged to suggest additional updates via email to phac.nd-mado.aspc@canada.ca.

\section{Authors' statement}

ST - Writing original draft, review and editing

AM - Review and editing

SM - Review and editing

\section{Conflict of interest}

None.

\section{Acknowledgements}

Thanks to the Canadian Notifiable Disease Surveillance System (CNDSS) provincial/territorial data providers for their annual collaboration on data submissions and to the disease program areas of the Public Health Agency of Canada's Infectious Disease Prevention and Control Branch for their input on case definition reviews.

\section{Funding}

This work was supported by the Public Health Agency of Canada.

\section{References}

1. Public Health Agency of Canada. Notifiable Diseases Online. PHAC; Ottawa (ON): 2018.

https://diseases.canada.ca/notifiable/

2. Government of Canada. Canada's 2018-2020 National Action Plan on Open Government. (Accessed 08-122019). https://open.canada.ca/en/content/canadas-20182020-national-action-plan-open-government

3. Carter A and The National Advisory Committee on Epidemiology Subcommittee. Establishing goals, techniques and priorities for national communicable disease surveillance. Can J Infect Dis. 1991; 2(1):37-40. DOl PubMed

4. Doherty JA; ACE Subcommittee on Communicable Diseases. Establishing priorities for national communicable disease surveillance. Can J Infect Dis 2000 Jan;11(1):21-4. DOI PubMed

5. Doherty JA. Final report and recommendations from the National Notifiable Diseases Working Group. Can Commun Dis Rep 2006 Oct;32(19):211-25. PubMed

6. Advisory Committee on Epidemiology and Division Disease Surveillance, Health Canada. Case Definitions for Communicable Diseases under National Surveillance. Can Commun Dis Rep 2000; 26S3. http://publications.gc.ca/ collections/Collection/H12-21-3-26-3E.pdf

7. Public Health Agency of Canada. Case Definitions for Communicable Diseases under National Surveillance. Can Commun Dis Rep 2009; 35S2. https://www.canada.ca/ content/dam/phac-aspc/migration/phac-aspc/publicat/ ccdr-rmtc/09pdf/35s2-eng.pdf

8. Public Health Agency of Canada. List of nationally notifiable diseases. PHAC; Ottawa (ON): 2018. https://diseases.canada. $\mathrm{ca} /$ notifiable/diseases-list

9. Canadian Public Health Laboratory Network. The laboratory diagnosis of Lyme borreliosis: guidelines from the Canadian Public Health Laboratory Network. Can J Infect Dis Med Microbiol. 2007;18:145-8. DOI PubMed 
Appendix 1a: Example output from Notifiable Diseases Online - campylobacteriosis and salmonella, rate per 100,000 population, 1991 to 2016

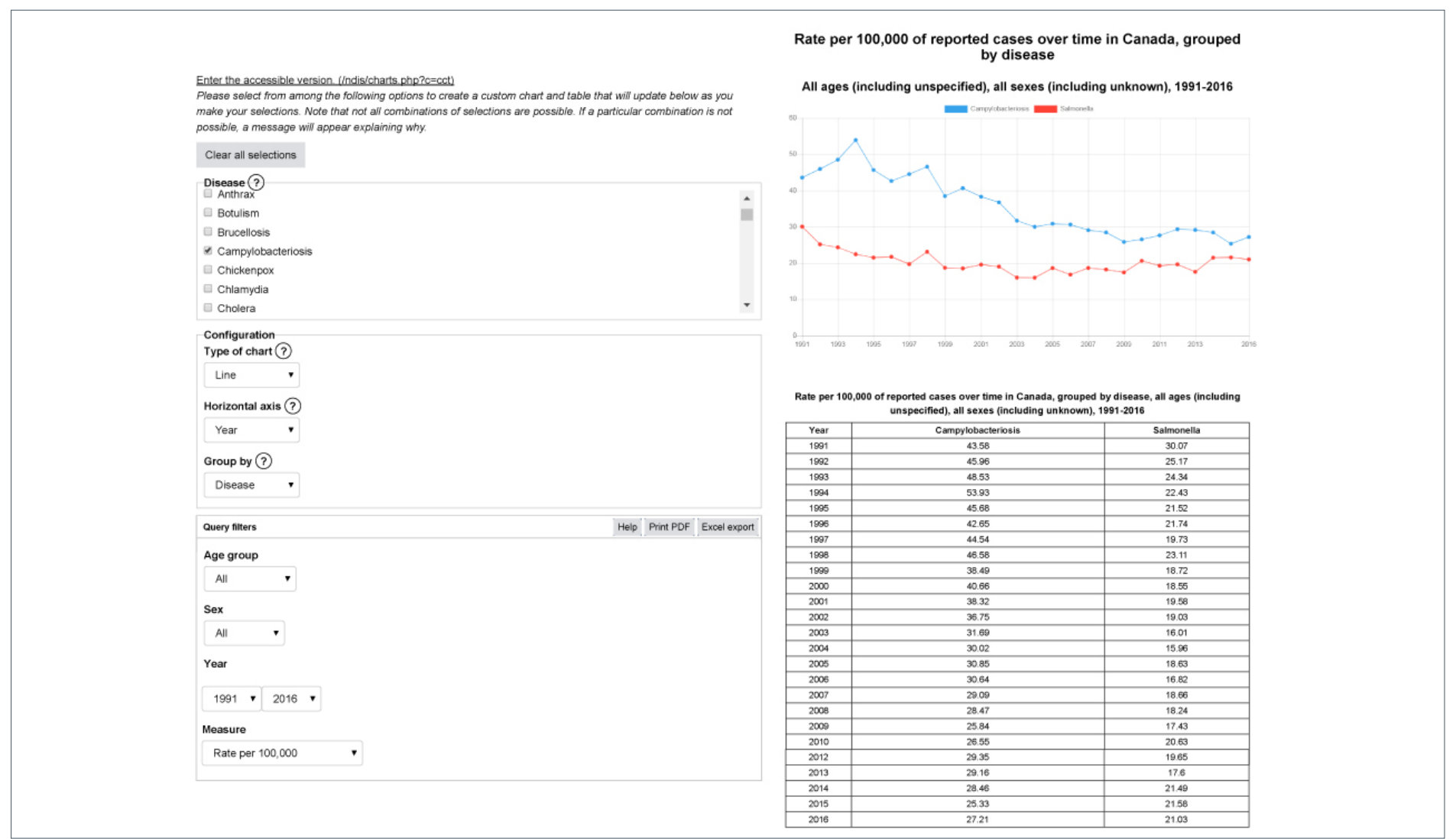

Appendix 1b: Example output from Notifiable Diseases Online - chlamydia and gonorrhea by age group, rate per 100,000 population, 2016

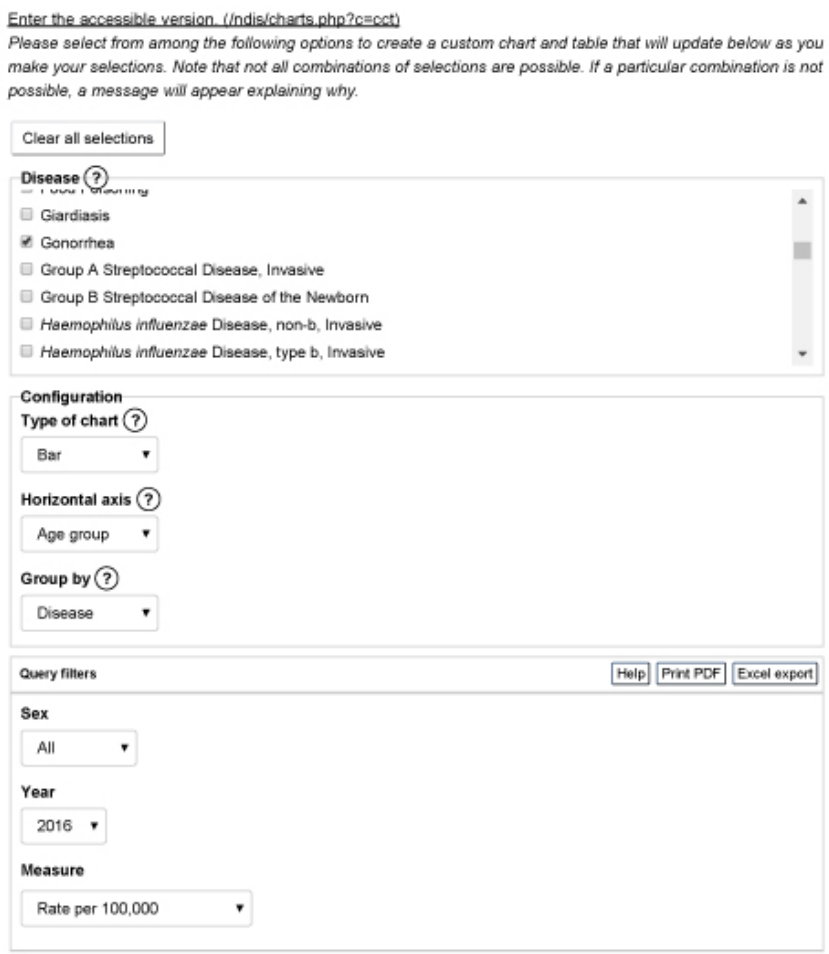

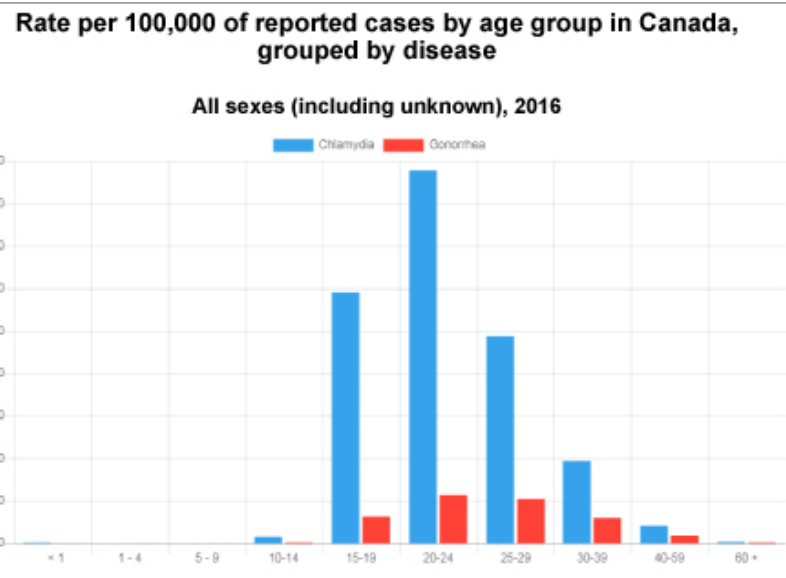

Rate per 100,000 of reported cases by age group in Canada, grouped by disease, all sexes (including unknown), 2016

\begin{tabular}{|c|c|c|}
\hline Age group & Chlamydia & Gonorriea \\
\hline$<1$ & 3.88 & 0.52 \\
\hline $1-4$ & 0.13 & 0.39 \\
\hline $5-9$ & 0.45 & 0.15 \\
\hline $10-14$ & 30.48 & 4.67 \\
\hline $15-19$ & $1,182.25$ & 126.55 \\
\hline $20-24$ & $1,756.67$ & 228.02 \\
\hline $25-29$ & 975.44 & 208.63 \\
\hline $30-39$ & 388.57 & 119.52 \\
\hline $40-59$ & 81.82 & 36.95 \\
\hline $60+$ & 7.08 & 4.8 \\
\hline
\end{tabular}

